\title{
USING BIM MODELS FOR THE DESIGN OF LARGE RAIL INFRASTRUCTURE PROJECTS: KEY FACTORS FOR A SUCCESSFUL IMPLEMENTATION
}

\author{
TIMOTHY NUTTENS ${ }^{1,2}$, VINCENT DE BREUCK ${ }^{1}$, ROBBY CATTOOR ${ }^{3}$, \\ KURT DECOCK ${ }^{4} \&$ ISABELLE HEMERYCK ${ }^{1}$ \\ ${ }^{1}$ TUC RAIL NV, Department Design, Unit Design Lines \& Track, Belgium. \\ ${ }^{2}$ Department of Geography, Ghent University, Belgium. \\ ${ }^{3}$ INFRABEL, Data Governance \& Project, Belgium. \\ ${ }^{4}$ INFRABEL, GIS \& CAD, Belgium.
}

\begin{abstract}
As already widely acknowledged in the construction industry, the use of a BIM model as single-pointof-truth during the design and construction phase of the project's lifecycle improves efficiency and reduces rework and extra costs. However, implementing the coordination and integration of different technical designs holds a lot of challenges. Combining different technical designs in one model in such a way that analyses, interface management and clash detection are possible, requires not only clear task descriptions and responsibilities for every stakeholder, but also a detailed workflow describing the required input, expected output of every technique and the intermediate deadlines during the design. Moreover, changes in the way the designs are made and specific configurations of the software tools are often needed to guarantee an optimal integration with the other parts of the design and to meet the firm's specific processes. This paper describes our experience gathered the last few years with the implementation of a BIM methodology supporting the design integration of different technical disciplines in large rail infrastructure projects. The focus lies on the implementation of available technical solutions to support our methodology, to improve design efficiency and to deliver high-quality integrated study designs. So far, our results show a successful implementation of BIM in our design department, integrating the design of all technical disciplines allowing us to follow the progress of the design, improve the communication within the project team and detect and solve clashes earlier in the design process. Key factors contributing to a successful BIM implementation are further explained and illustrated with practical examples.
\end{abstract}

Keywords: BIM implementation, collaborative practices, design coordination, integrated model, multidisciplinary projects, rail infrastructure.

\section{INTRODUCTION}

Using BIM models in the construction industry is no longer an exception in large infrastructure projects; the advantages are becoming more and more obvious. BIM for infrastructure solutions support the industry's search for improved efficiency and design quality, leading to less rework and delays on site and minimizing unexpected costs [1-4]. This improved efficiency deals with the expected growth of the need in infrastructure investments but fewer available resources [5, 6]. Whether the design company uses a BIM model to deliver a highquality design or the contractor for preparing and following the project's execution or other stakeholders, based on a common BIM Execution Plan, each application of BIM comes with its own challenges and necessary adaptations to make it suitable for that specific project and group of users [7, 8].

A lot of research and published case studies investigate and illustrate the implementation of BIM for infrastructure projects. They focus on specific projects and the key factors that influence the success of BIM for these projects, mainly from the perspective of a design team as a whole or the relationship between the design team and the contractor [2,9]. They all 
highlight the importance of the quality of the model data meeting the project's needs, adding the necessary object information and a clear communication during the design study.

Our BIM experience is based on using BIM for multidisciplinary large railway infrastructure projects (mainly in Belgium), where BIM models are used in the design phase for the integration of parts of the design from all technical disciplines and using these integrated models for interface checking between the technical disciplines (design review and analysis) and clash detection. Allowing different technical designs to be combined in one model in such a way that design coordination, analyses, interface management and clash detection are possible, requires not only clear task descriptions and responsibilities for every stakeholder, but also a detailed workflow describing the required input, expected output of every technique and the intermediate deadlines during the design. Moreover, to meet the firm's processes described in the BIM Execution Plan and to assure an optimal integration with the other parts of the design, changes in the way the designs are made and specific configurations of the software tools are often needed. Our experience confirms the general factors for success from earlier research, but this paper complements the existing research by adding specific points of attention in situations with a design team consisting of different technical disciplines and design units, and when improving the internal design team communication and dealing with different levels of 'BIM maturity' of the units are critical factors. Highlighting these factors can hopefully help similar design firms with improving the success rate of BIM in the construction industry.

Chapter 2 gives more information about the activities of our firm and how we are generally implementing BIM for our projects. Chapter 3 illustrates in detail what we have experienced as important factors for successfully implementing BIM in a multidisciplinary design team.

\section{BIM IMPLEMENTATION}

This chapter gives more information about the activities of TUC RAIL and how the use of BIM is implemented for large rail infrastructure projects. Also, more details about the used tools to support our methodology are mentioned.

\subsection{Activities of TUC RAIL}

TUC RAIL, a Belgian multidisciplinary engineering and project management firm, specialises in railway infrastructure projects. Since 1992, TUC RAIL has built a large expertise within the railway business, specifically on infrastructure level. Its activities cover the whole project cycle from feasibility study until detailed design and technical plans, providing project management for large infrastructure projects and construction site supervision.

Working on large and complex projects on one of the world's busiest railway networks, both for extending the Belgian rail network with new railway connections and for modernising the often complex existing connections within very restricted areas has allowed TUC RAIL to acquire a lot of expertise. In Belgium, TUC RAIL is mainly working for the 'Build Department' of Infrabel, the Belgian rail infrastructure manager, but the built-up expertise is also being used to provide services for foreign projects.

Some examples of rail infrastructure achievements of TUC RAIL:

- Construction of the Belgian High Speed Line Network (first parts in service in 1997-completely in service in 2009): $200 \mathrm{~km}$ of new lines and more than $60 \mathrm{~km}$ of upgraded lines, including the necessary tunnels, viaducts, bridges and all rail infrastructure equipment.

- Diabolo connection (in service in 2012): two $1 \mathrm{~km}$ long drilled tunnels under Brussels National Airport with all necessary rail infrastructure equipment (Fig. 1a). 
- Liefkenshoek Rail Link (in service in 2014): two $7 \mathrm{~km}$ long drilled tunnels with all rail infrastructure equipment to improve the freight traffic in the port of Antwerp.

- Schuman-Josaphat Tunnel (in service in 2016): a new tunnel of $1250 \mathrm{~m}$ under the European quarter in the heart of Brussels with all rail infrastructure equipment (Fig. 1b).

- Concentration of signal boxes and installation of the ETCS system on the whole Belgian rail network (ongoing).

- Renovation of the North-South underground connection in Brussels concerning fire safety, ventilation etc. (ongoing) (Fig. 2a).

- Modernisation of the Axe 3 railway in the hilly Walloon region of Belgium (ongoing) (Fig. 2b).

- High-Speed Line Network in France: Bretagne - Pays de la Loire (ongoing).

TUC RAIL combines all necessary technical disciplines for railway infrastructure projects in one engineering firm such as civil engineering for designing steel or concrete bridges, viaducts, tunnels or smaller civil technical structures; railway design; road and environmental design; signalling; catenary; high and low voltage; hydraulics and earthworks. The Design Department also contains divisions working on topography and photogrammetry, expropriations, geological investigations, fire safety and HVAC. Since 2013, a BIM division was set up to start implementing the use of BIM for improving the quality and efficiency of the delivered designs.

\subsection{BIM methodology and tools}

The use of integrated BIM models in de Design Department of TUC RAIL started with a proof of concept in 2013 and was taken in production in 2014. The BIM process that was elaborated envisioned a better integration of the designs of the different technical disciplines and an integrated 3D model that could improve the communication within the project team
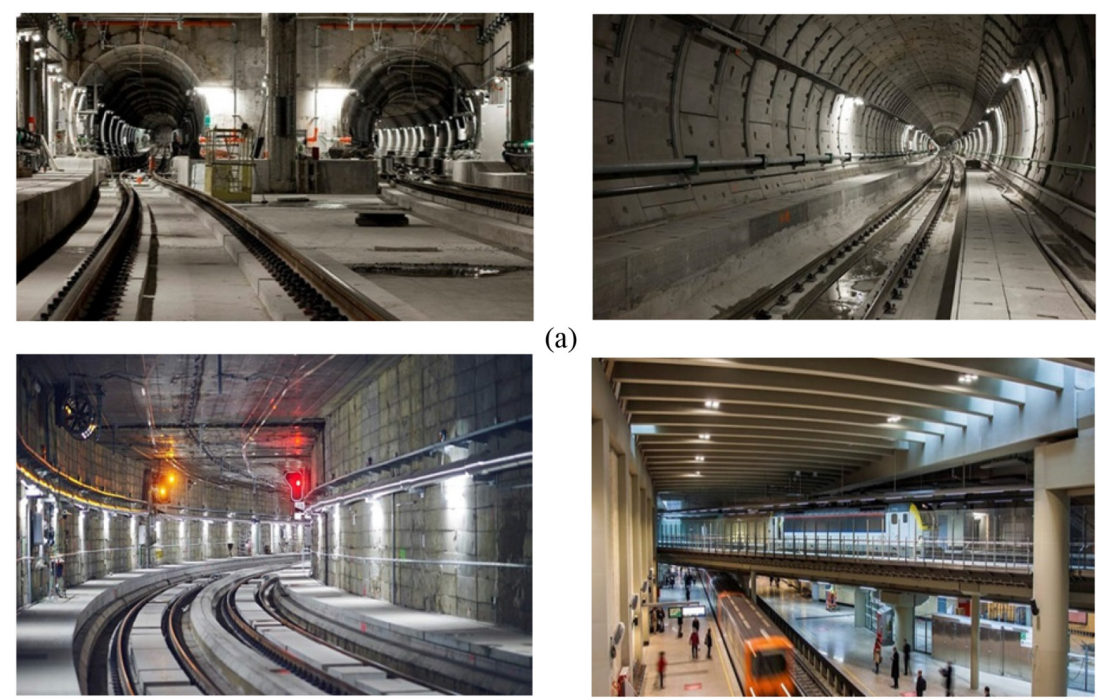

(a)

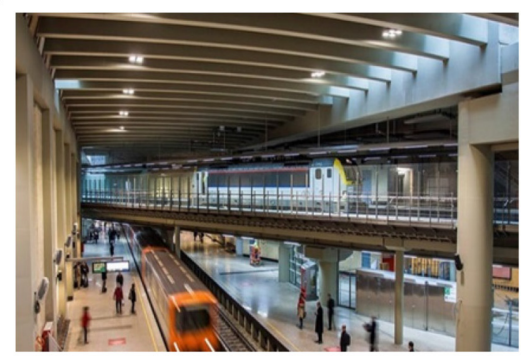

(b)

Figure 1: Examples of rail infrastructure achievements of TUC RAIL. (a) Diabolo Tunnel, Brussels; (b) Schuman-Josaphat Tunnel, Brussels (Source: TUC RAIL nv, 2017). 


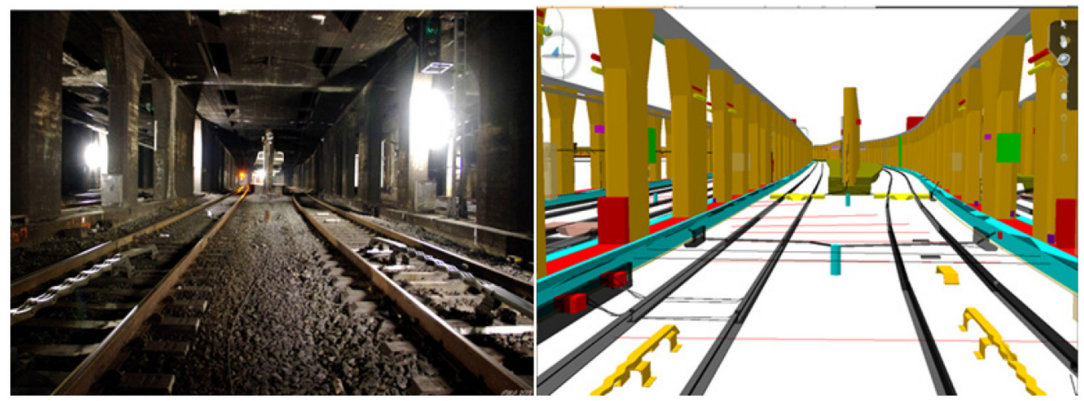

(a)

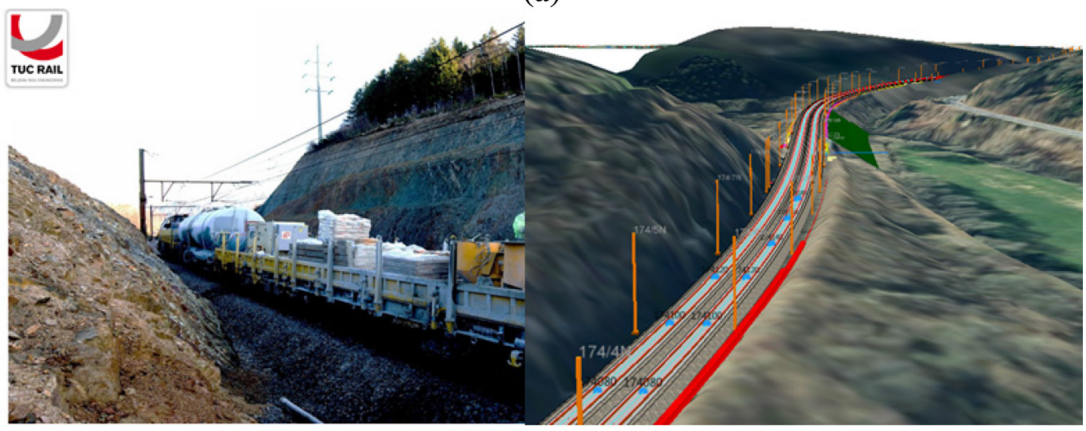

(b)

Figure 2: Examples of rail infrastructure projects of TUC RAIL (left) with the corresponding BIM model (right). (a) Renovation of the North-South connection, Brussels; (b) Modernisation of the Axe 3, Walloon Region (Source: TUC RAIL nv, 2017).

and would allow thoroughly analysing all interactions between the disciplines, detecting as many clashes or problems as possible in advance. The main goal of this better design coordination, improved communication and early clash detection was to avoid rework during execution and to minimize delays on site, resulting in projects delivered within time and budget.

Although these goals are not that different from the general acknowledged goals of why construction companies should make the switch to using BIM, the implementation process in a design firm with rather fragmented units for every technical discipline and with limited project communication and design review of the overall design, revealed aspects that had an important impact on the success of the BIM implementation in our firm.

The design tools of the different technical disciplines were not changed with the implementation of BIM. To build up the integrated BIM model for a project, a central database ('BIM server' - Trimble Quadri) is used on which all 2D and 3D design data of the different units is centralized. Projects on the BIM server are separated per geographical zone. Different projects located in the same geographical zone are combined in one BIM model. The BIM client software (Trimble Novapoint Base) allows users to import their design data in the central database, to visualise and analyse the integrated model and to export a part of the data if necessary.

Moreover, a detailed and up-to-date image of the existing situation and existing conditions modelling is added to the BIM model (e.g. topographical measurements, orthophotos taken with a drone, laser scanning point clouds...), together with any other available graphical information that could have an influence on the realisation of the project. These other data 
sources can range from WMS services with base maps or orthophotos to cadastral information, environmentally protected areas, soil tests, bomb risk zones etc. This integrated model of both the existing situation and project design allows us to go through the whole project, checking it for clashes and possible problems during execution (e.g. site access roads that are too narrow or too steep for the trucks). Besides these BIM tools, a combination of guidelines and workflows supports the use of BIM in the whole design department. These guidelines and workflows describe the different user roles, responsibilities and interactions between the design disciplines. The BIM workflow as it is elaborated within TUC RAIL describes in detail which technique has to provide which input in every stage of the project. As a lot of the techniques need input from others to study their part of the project, a clear workflow and critical path are needed to be able to meet the project deadlines.

To improve the communication within the project team, regular team meetings are organised, discussing the progress and content of the BIM model and assessing all interfaces between the technical disciplines. Also, additional tools are used to ease this communication and to document and follow up any detected clashes or problems in the BIM model. By using the Trimble Quadri EasyAccess tool, an online conversation is set up for every clash to discuss the problem and possible solution, with a visual link in the BIM model. By changing the status of this conversation during the discussion, the whole project team can follow the progress of the solution. As this EasyAccess tool is stored in the cloud, the clash discussions and solutions are also remotely accessible.

\section{KEY FACTORS FOR A SUCCESSFUL BIM IMPLEMENTATION}

This chapter describes the key factors, both on company level and on project level, that contribute to a successful and step-by-step introduction of BIM in a multidisciplinary large design firm. The key factors on company level focus on some more general organization aspects, which we have encountered or have experienced as being important. These aspects are not linked to the tools that are being used, but are more linked to people management and change management in a firm with different design units, each specialized in their own technical field and not always used to closely collaborate and communicate during the design study of a project. The key factors on project level contain much more practical examples. Although these factors are illustrated with software specific images, the key factors themselves are generally applicable.

\subsection{Key factors on organisation level}

When implementing BIM as a whole new process in a firm, a clear communication of the $\mathrm{BIM}$ vision and full support of the management is essential. This vision and its first communication to all departments and colleagues that will be closely or from far involved in the BIM process is the most important opportunity to get everyone on board. When this vision is badly explained, the success of the BIM implementation can really be endangered or slowed down. By getting everyone on board from the first moment, you are assured that they all know in which way the firm is moving, what the goals are in the end (long-term vision) and which intermediate steps have to be taken to reach these goals (short- and medium-term vision). Within TUC RAIL, experience clearly showed the importance of communicating the BIM vision and impact of the new methodology on existing processes to all colleagues in the firm. Even colleagues of which you think they will not be directly impacted by this new 
methodology at least have to have an idea of which way the company is evolving and what new ways of working are being implemented, because on the long term they too will be involved in some way.

Although maybe not all details of the impact on the different departments are known at the beginning, the first BIM presentations should already give an idea of what the impact will be on every department. When working in a firm with different design units which all have their specific non-uniform way of working, the changes for one unit can be much larger than the changes for another unit. It is important to take this difference of impact level into account in all communications.

Further on during the BIM implementation and the application of the new processes, every communication should be 'tailor made'. All support, training courses, workflows or manuals provided by the 'BIM support unit' have to focus on the specific target audience. The impact of implementing BIM at TUC RAIL for example was different for every design unit. For some of them, smaller adjustments to their internal workflows were sufficient to take the first steps of the BIM implementation. For other units, much more adjustments or complete changes were needed. Moreover, even within a design unit, differences in enthusiasm and capability of implementing new technologies between colleagues exist. These differences should also be reflected in the intensity of the support by the BIM support unit, in the amount and the content of the training courses that are organised and the 'live' presence of the BIM support unit with the specific users.

Depending on the size of the unit, choosing one or two so-called 'Key Users' can be very helpful to get the necessary information flows work well. These key users are the ideal way to efficiently get information from the BIM unit to all users, and vice versa. They are an easily reachable contact person for a user in his own design unit. He can collect all positive and negative feedback, questions and ideas for improvement and communicate them further to the BIM unit. However, it is important that the selected key users believe the company's BIM vision and fully participate in further implementing it in their own unit.

\subsection{Key factors on project level}

When working on a specific BIM project with different technical disciplines, clear guidelines on the desired input, deliverables, Level of Detail and timing are needed. Templates, workflows or decision trees can be very helpful tools, as long as they take into account the different levels of BIM knowledge and BIM implementation of every design unit and the specific needs of the project. Clear decisions at the beginning of the project on what is needed, what is desired and what is possible within time and budget restrictions avoid confusion and misunderstandings. Tools like a detailed BIM workflow and BIM Execution Plan can be used for that.

Clear communication supports an optimal and efficient study of the project. Implementing BIM during a design is more than just using a tool; it is often a new way of collaborating and communicating with colleagues. Guiding and supporting this change is crucial for a successful use of BIM within a firm. Therefore, for each project, regular project team meetings should be organised. These meetings have different goals. First, they allow the team leader to get an insight in the progress of the study of every technical discipline, in problems that should be addressed or in blocking elements that prevent the study of moving forward. Second, the technical risk analysis of the design made at the start of the project can be further detailed and followed up. The BIM model is an ideal tool to provide an integrated 3D view 


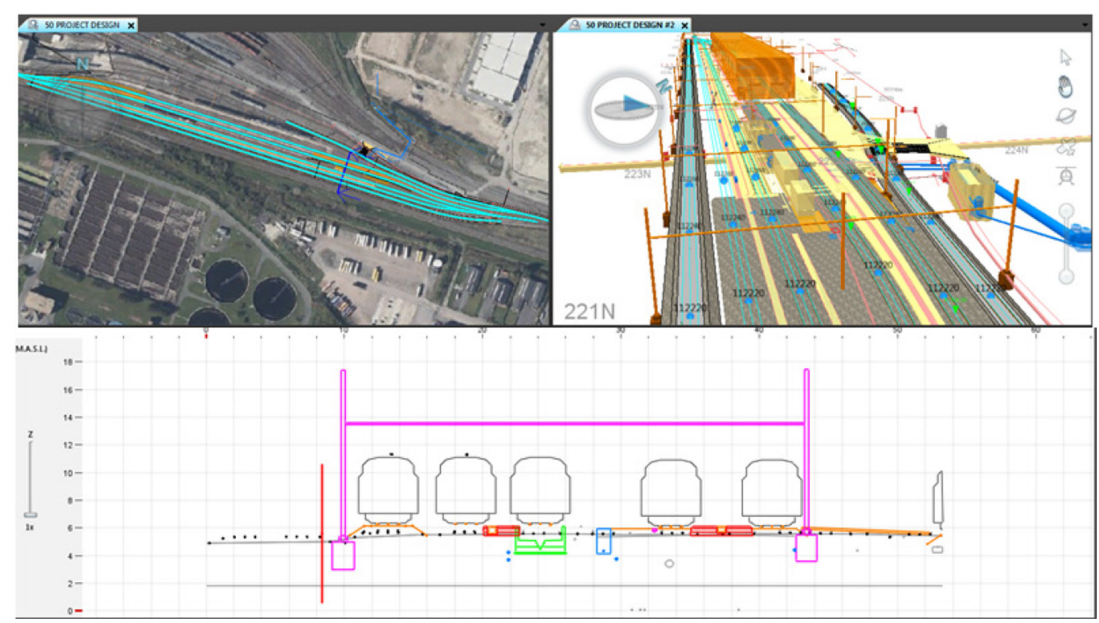

Figure 3: Overview of a BIM model. 2D view of the project (upper left); 3D view (upper right) and a cross-section (lower example).

for supporting any questions or discussions on these points. Third, the BIM model can be used to go through the whole project based on 2D and 3D overviews and cross-sections to thoroughly analyse the design that's been developed. (Fig. 3) For any problems, clashes or additional risks detected during this analysis a clear responsible and timing should be defined for resolving or following up this issue. For the BIM support unit, these meetings are one of the occasions to get an insight in the use of the BIM tools in every design unit and to collect information on issues, bugs and problems with implementing it in their work.

Implementing BIM in a large firm with different design units, each with their specific technical specialty and design tools, own developed tools and internal guidelines, involves a lot of changes to be made. Starting with BIM and expecting that all these changes and a complete uniformity are achieved from the start of the implementation is unrealistic. Therefore, minimal data requirements can be defined, so that an integration of the different design models is possible and that changes in internal workflows can be implemented step-by-step, as the BIM implementation further proceeds and as experience during the first BIM projects grows. Again, the difference in 'BIM readiness' of every unit and their experience with 3D designs will determine how much effort each of them will have to do to achieve these minimal BIM requirements. As already stated, this on its turn will have an influence on the amount and the content of the BIM support and training courses that are needed.

The minimal data requirements of the BIM model should allow all users to at least get an insight in the most important aspects of the data. For large infrastructure and multidisciplinary projects, this key information of the objects can be different than for companies working on e.g. BIM for buildings. The needs of what information is required to be able to analyse the model and review the design can be quite different between those two BIM applications. From our experience, we use three key information elements for our projects. First, the status of the object: is it the existing situation or project design and to which design study does this object belong? (Fig. 4) Including elements of ongoing designs or project executions in the same geographical zone can also be important to assess the new design and to avoid problems or clashes, but a clear distinction between the different design studies is then necessary. 


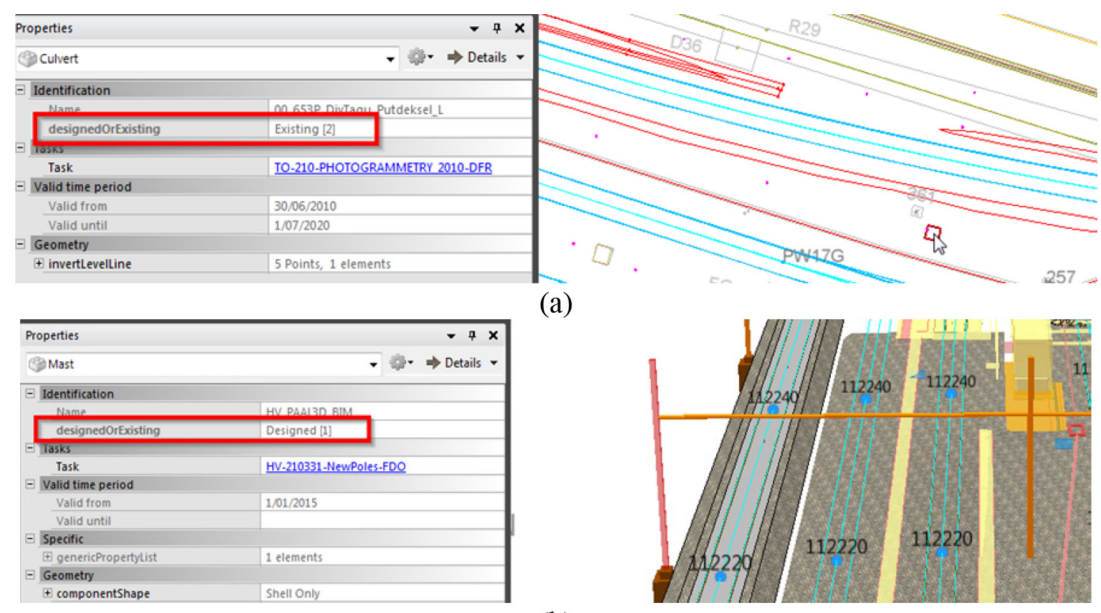

(b)

Figure 4: Status of elements in the BIM model: Existing situation (a); Project design (b).
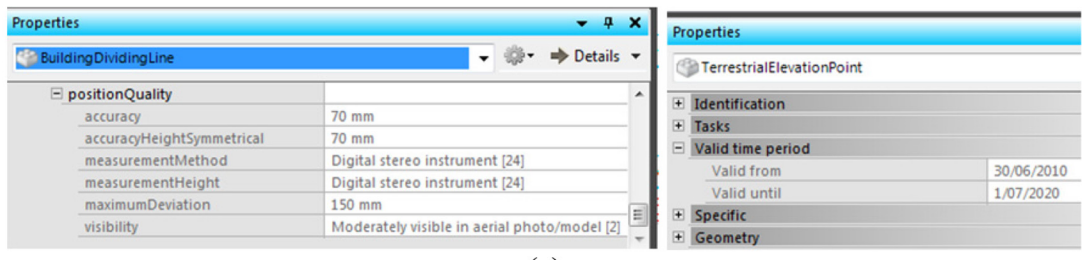

(a)

\begin{tabular}{|c|c|c|}
\hline \multicolumn{3}{|l|}{ Properties } \\
\hline Q8 RailwayTrack & - & $r$ \\
\hline I positionQuality & & . \\
\hline accuracy & $15 \mathrm{~mm}$ & \\
\hline accuracyHeightSymmetrical & $15 \mathrm{~mm}$ & \\
\hline measurementMethod & Measured in terrain with total station [11] & \\
\hline measurementHeight & Measured in terrain with total station [11] & \\
\hline maximumDeviation & $25 \mathrm{~mm}$ & \\
\hline visibility & Fully visible/locatable in terrain [0] & \\
\hline
\end{tabular}

(b)

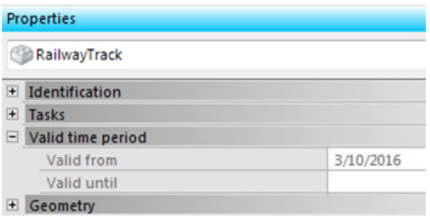

+ Geometry

Figure 5: Object properties describing the accuracy and the date of the measurements: photogrammetric measurement (a); topographic measurement (b).

Second, the accuracy of the measurements of the existing situation and the date on which the measurements were taken (Fig. 5). As we use photogrammetric data, topographic data, laser scanning point clouds or photo modelling, each with their specific levels of accuracy, it is important to know how accurately an object of the existing situation is positioned, specifically when working in restricted areas. Moreover, the date and accuracy of the measurements indicate whether or not there is a need for new measurements to get a more recent or more accurate view of the existing situation.

The third information tells us to which technical discipline an object belongs: is it an element of high voltage, signaling, civil engineering, hydraulics, road or rail infrastructure...? Using this information, we are able to visualize every object according to its technical discipline. This helps us during the review of the design, the clash detection and the interface management between the different technical disciplines. (Fig. 6) 


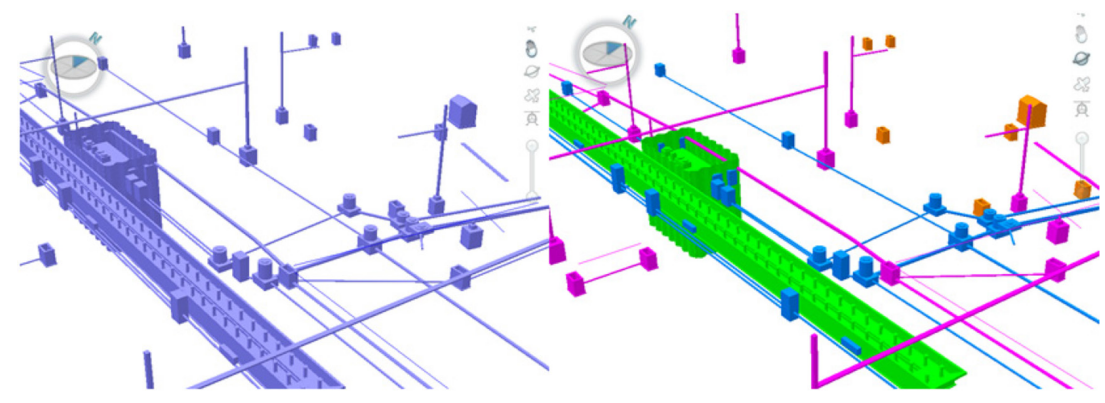

Figure 6: Using the information of the technical discipline to better visualize the objects in the BIM model : default view (left) ; view per technical discipline (right) - civil engineering (green), hydraulics (blue), signaling (orange) and high voltage (pink).
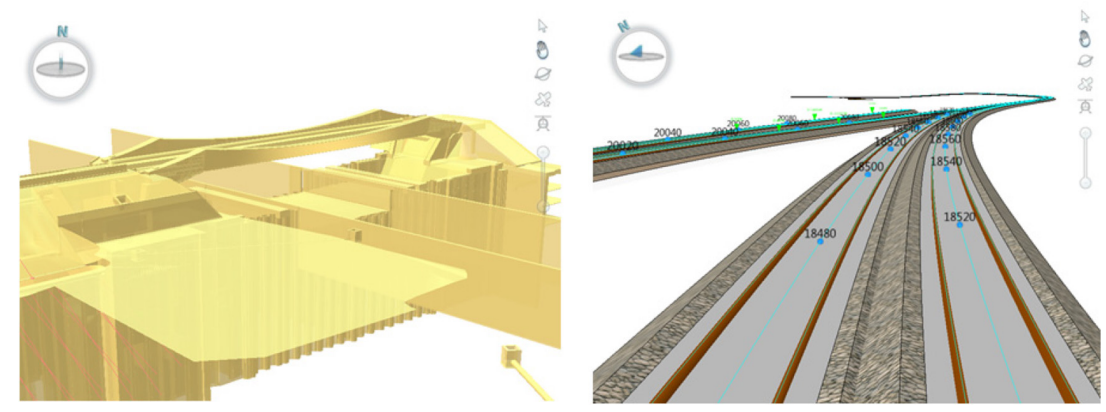

Figure 7: Linking the imported data in the BIM model with specific object types in the software's library: no specific object types used (left); using specific object types (right).

Besides these basic elements of information, the more extra information that can be added to an object, the more clearly and distinguishably the objects can be visualized, categorized and analysed. Different design units within our firm already add additional information to the objects they import in the BIM model, depending on the level of BIM implementation in their unit. For example, in the railway design, every element of the rail design is linked to a specific object type of the software's object library, which allows for the ballast bed, rails etc. to be clearly visible. This distinction allows even better visualizing and interpreting the different design elements of the railway study, compared to parts of the design where such links to specific object types is not yet used. (Fig. 7)

For example, signaling and high voltage add the signal's name or pole number to the object for a better identification. They also add the size of the cableways they designed, which allows a more detailed visualization and makes the BIM model ready for further analyses in the future, such as automatic extraction of quantities of specific construction elements. (Fig. 8). In more advanced projects, additional information on the phasing of the construction is added to the objects. This allows analysing and clash detection in the BIM model phase per phase to guarantee a correct execution on site. (Fig. 9) These more advanced levels of object intelligence, visualization and possible analyses also serve as in house examples for other design units, based on specific and real life projects, to show in which way they can and should evolve. 

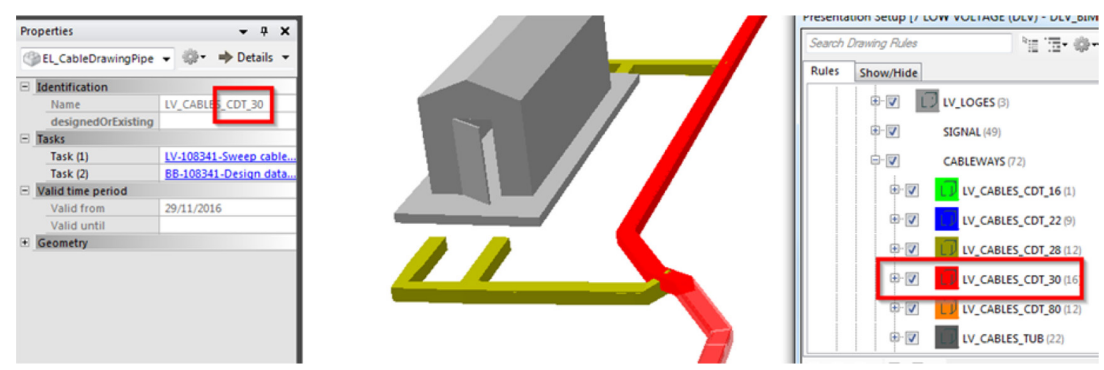

Figure 8: Using the additional information of the cableway dimensions to categorize them per dimension type for better visualization.

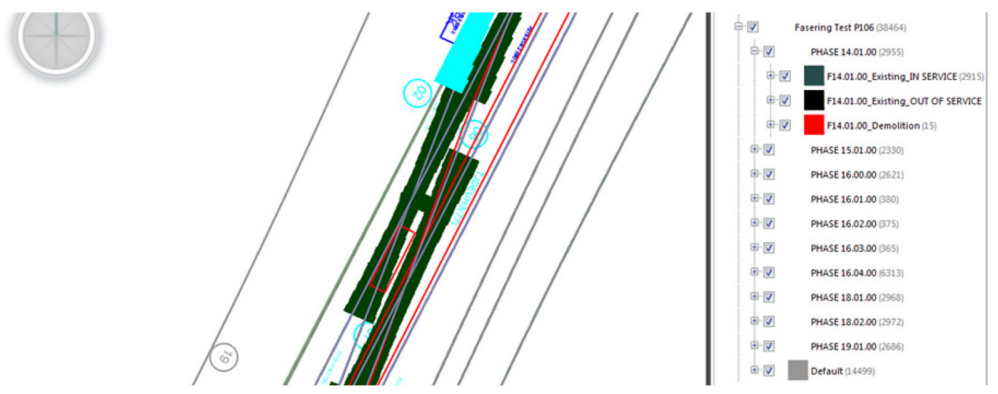

Figure 9: Information about the phasing used to visualize each element in the correct phase.

\section{CONCLUSIONS}

Our experience in the last few years with the implementation of a BIM methodology for the integration of $2 \mathrm{D}$ and $3 \mathrm{D}$ designs has led to a number of key factors that we consider as important or even crucial for the success of implementing BIM. Our main goal of using BIM is to improve design integration, internal project team communication and clash detection to avoid rework during execution of the project and to minimize delays on site. These improvements result in higher quality projects delivered within time and budget. In our BIM implementation, the focus lies on using BIM for the integration of the designs of different technical disciplines for large rail infrastructure projects and dealing with different levels of 'BIM maturity' of every design unit in the project team.

There are a number of key factors, on company level as well as on project level to contribute to a successful and step-by-step introduction of BIM in a multidisciplinary large design firm. On company level, these key factors focus on more organizational aspects, such as a clear communication of the BIM vision to all colleagues in the firm and taking into account the difference of impact level on these colleagues in all communication. Furthermore, during the BIM implementation, all communication, manuals, training courses and workflows should remain 'tailor made', focussing on the target audience. Key users can be helpful to have an efficient and continuous link between all user groups and the BIM support unit. Guiding the change management and taking into account the specificity of the company is crucial when implementing BIM.

On project level, clear decisions and guidelines at the beginning of the project are necessary, describing the project's needs for every technical discipline. Regular project team 
meetings, based on the BIM model as a tool to have a 3D view on the project, allow a thorough follow-up project's progress. Minimal requirements of the BIM data should be defined such as status of the object, accuracy and date of the measurements of the existing situation and information to which technical discipline an object belongs. They allow all users to get an insight in the most important aspects of the data and they allow a step-by-step BIM implementation in the different design units, depending on their BIM maturity. Units with a higher BIM maturity can already add additional information to their designs, allowing more advanced BIM analyses, while still maintaining the integration with the other technical disciplines.

Highlighting these factors can hopefully help further using BIM in similar design firms and improving the success rate of BIM in the construction industry. Implementing BIM in our company has already lead to a much closer collaboration between our design units, now working even more as one team to deliver high-quality design. Our further BIM developments will mainly focus on adding more uniformity and intelligence to the models, allowing more analyses and allowing our clients to further use the models for the asset management of their infrastructure.

"Information published by TUC RAIL in the present document is informative and noncontractual. All rights reserved".

Copyright TUC RAIL / Infrabel

\section{REFERENCES}

[1] Azhar, S., Building Information Modeling (BIM): Trends, benefits, risks, and challenges for the AEC industry. Leadership and Management in Engineering, 11(3), pp. 241-252, 2011. https://doi.org/10.1061/(asce)lm.1943-5630.0000127

[2] Barlish, K. \& Sullivan, K., How to measure the benefits of BIM - A case study approach. Automation in Construction, 24, pp. 149-159, 2012.

https://doi.org/10.1016/j.autcon.2012.02.008

[3] Gledson, B.J. \& Greenwood, D.J., Surveying the extent and use of 4D BIM in the UK. ITcon, 21, pp. 57-71, 2016.

[4] Kim, K. \& Teizer, J., Automatic design and planning of scaffolding systems using building information modeling. Automation in Construction, 28, pp. 66-80, 2014. https://doi.org/10.1016/j.aei.2013.12.002

[5] Suchocki, M., BIM for Infrastructure: integrating spatial and model data for more efficient contextual planning, design, construction and operation. WIT Transactions on The Built Environment, 149, WIT Press: Southampton and Boston, pp. 305-315, 2015.

[6] Suermann, P.C. \& Issa, R.R.A., Evaluating industry perceptions of building information modelling (BIM) impact on construction. ITcon, 14, pp. 574-594, 2009.

[7] McArthur, J.J. \& Sun, X., Best practices for BIM execution plan development for a publicprivate partnership design-build-finance-operate-maintain project. WIT Transactions on the Built Environment, 149, WIT Press: Southampton and Boston, pp. 119-130, 2015.

[8] Oh, M., Lee, J., Hong, S.W. \& Jeong, Y., Integrated system for BIM-based collaborative design. Automation in Construction, 58, pp. 196-206, 2015. https://doi.org/ 10.1016/j.autcon.2015.07.015

[9] Bråthan, K. \& Moum, A., Involvement matters: BIM implementation at project level in the AEC industry. WIT Transactions on the Built Environment, vol. 149, WIT Press: Southampton and Boston, pp. 157-168, 2015. 